\title{
Retraction Note: Collaborating with Patients on Firearms Safety in High-Risk Situations
}

\author{
Michael O. Miller • Gary R. VandenBos
}

Published online: 2 March 2021

(C) National Register of Health Service Psychologists 2021

Retraction Note: Journal of Health Service Psychology (2020) 46:165-172

https://doi.org/10.1007/s42843-020-00022-1

The Editor-in-Chief and the authors, VandenBos and Miller, have retracted this article as it significantly overlaps with an unpublished manuscript by Amy Barnhorst and Rocco Pallin. Barnhorst and Pallin previously submitted the unpublished manuscript, and it was handled by VandenBos as managing editor, before being withdrawn by Barnhorst and Pallin.

Miller and VandenBos have stated that all events regarding the unpublished manuscript occurred before Miller was invited to participate in the project. Miller has stated he was not aware of the unpublished manuscript until after the article was published. VandenBos accepts full responsibility for the overlap. 